\title{
A influência do determinismo ambiental no processo de mudança e adaptação estratégica numa empresa distribuidora de gás liquefeito de petróleo
}

\author{
Luciano Vieira* \\ Jorge Oneide Sausen** \\ Lisiane Caroline Rodrigues Hermes**
}

\begin{abstract}
Resumo
O presente artigo apresenta a metodologia e os resultados de um estudo cujo objetivo é descrever o processo de adaptação e mudança estratégica. Para tanto, analisou-se a influência do determinismo ambiental e a capacidade de escolha estratégica em uma empresa distribuidora de gás liquefeito de petróleo, no período de 1993 a 2013. Trata-se de um estudo de caso único, de abordagem qualitativa dos dados com análise histórica e longitudinal. Os resultados indicaram três períodos estratégicos e confirmaram que, embora o determinismo ambiental tenha sido decisivo no reposicionamento estratégico da empresa, seus administradores conseguiram exercer capacidade de escolha estratégica nos três períodos identificados.
\end{abstract}

Palavras-chave: Processo de mudança estratégica. Adaptação estratégica. Determinismo ambiental.

* Aluno do Programa de Pós-Graduação Strictu Sensu em Desenvolvimento - Universidade Regional do Noroeste do Estado do Rio Grande do Sul (Unijuí), Brasil. Bolsista Capes - Prosup. E-mail: contato.luvieira@yahoo.com.br

** Professor do Programa de Pós-Graduação Strictu Sensu em Desenvolvimento - Universidade Regional do Noroeste do Estado do Rio Grande do sul (Unijuí), Brasil. E-mail: josausen@unijui.edu.br

*** Aluna do Programa de Pós-Graduação Strictu Sensu em Desenvolvimento - Universidade Regional do Noroeste do Estado do Rio Grande do sul (Unijuí). Professora convidada na Faculdade de Ciências Econômicas, Administrativas e Contábeis da Universidade de Passo Fundo (FEAC/UPF), Brasil. E-mail: lisianehermes@upf.br

http://dx.doi.org/10.5335/rtee.v21i44.5359

Submissão: 25/08/2014. Aceite: 26/02/2015. 


\section{Introdução}

O ambiente mercadológico está cada vez mais competitivo e, em uma perspectiva tradicional (WHITTINGTON, 2002), as empresas precisam encontrar alternativas inovadoras para construir processos de melhoria contínua e contemplar ações para mudança organizacional. Nessa perspectiva, as constantes transformações no panorama político, econômico, cultural, tecnológico, demográfico e ecológico têm instigado alternância nas estratégias empresariais (HALL, 1984).

A compreensão da organização em uma perspectiva multidisciplinar confunde-se com a própria natureza do ser humano, revelando uma multidimensionalidade que, em maior ou menor grau, favorece a capacidade de adaptação às mudanças. Dessa forma, a estabilidade e a previsibilidade cedem espaço para a flexibilidade e a dinamicidade (QUERINO; MORAES, 2014).

As organizações, independentes do setor de atividade, sofrem influências ou influenciam, devem adequar-se a legislações, tributos, regimentos, são socialmente responsáveis ou se adequam a esse contexto, enfim, estão em permanente processo de mudança, adequação e transformação a fim de permanecerem atuantes no mercado.

O tema adaptação e mudança estratégica não é recente nem tampouco seus conceitos básicos são atuais. No entanto, surgem novas técnicas e teorias para facilitar a condução desse processo (LOPES; STADLER; KOVALESKI, 2003). Mintzberg, Ahlstrand e Lampel (2000) avaliam que, assim como existem diferentes classificações para a formulação de estratégias, existem também diferentes abordagens de mudança estratégica.

Nesse processo, os fatores externos à organização, no contexto dos ambientes geral e específico, retêm fortes influências no comportamento da organização (SAUSEN, 2003; SAUSEN; TRETER; WBATUBA, 2004; RINGON; OLIVEIRA, 2004). Dessa forma, as mudanças estratégicas aparecem como consequências da interpretação que os gestores fazem do ambiente, ou seja, de uma percepção e interpretação particular das condições objetivas dos ambientes geral e específico (DIVERIO; OLIVEIRA, 2006).

Bandeira-de-Mello e Cunha (2004), ao pesquisar uma empresa de edificações a partir de seu contexto histórico, constataram que a adaptação estratégica da firma a um ambiente turbulento e com forte influência governamental pode ser explicada, na ótica dos dirigentes, por um processo social denominado administração do risco, no qual a busca por posições seguras e livres de risco são priorizadas em detrimento da maximização de resultados. 
Já para Rossetto e Rossetto (2005), o processo de adaptação estratégica sob a perspectiva institucional e a dependência de recursos propõem aspectos de complementariedade entre as teorias, desencadeando visões diferentes sobre a influência do ambiente nas organizações, possibilitando um amplo cenário para explicar as distintas estratégias definidas pelos tomadores de decisão.

De acordo com Schmidt, Costa e Freitas (2014), ao estudar a cadeia produtiva coureiro-calçadista, os autores identificaram que o setor tem passado por adaptações significativas na sua forma de operação em face às profundas mudanças ocorridas no ambiente competitivo internacional, o que exige das organizações uma nova visão sobre seu posicionamento estratégico. Não obstante este cenário propõe que as empresas adotem ações estratégicas que lhes permita a adaptação às mudanças ambientais existentes no mercado.

Sendo assim, considera-se que a adaptação estratégica ocorre a partir de um processo no qual a organização vai desenvolvendo suas estratégias para melhor se adaptar ao ambiente. Hrebiniak e Joyce (1985) definem adaptação estratégica como um processo dinâmico que resulta da força relativa e do tipo de poder ou dependência existente entre a organização e o ambiente.

Por sua vez, a mudança estratégica pode ser conceituada como qualquer transformação de natureza estrutural capaz de gerar impacto em partes ou no conjunto da organização, e, na maioria das vezes, são pequenas e temporárias, não exigindo respostas estratégicas frequentes (MINTZBERG, 1998).

A mudança estratégica tem sido um dos principais diferencias para a manutenção das organizações no mercado, trazendo, inclusive, reflexos no desenvolvimento econômico e social de uma região/país. Pettigrew (1987) enfatiza que embora sob pressão ambiental, as organizações possuem condições de fazer escolhas, quanto às suas ações estratégicas, mesmo que elas sejam de alguma forma limitada pelo contexto. Diversas organizações sobrevivem porque os fatores influenciadores de sua manutenção no mercado são contornados pelas adaptações estratégicas postas em prática, as quais exigem alterações também nas estruturas organizacionais.

O processo de adaptação estratégica sob o contexto de mudanças é enfatizado por alguns teóricos a partir do determinismo ambiental e do voluntarismo (BERNARDES; SÁ, 2009).

A influência do determinismo ambiental nas organizações é discutida desde a década de 1960 (EMERY; TRIST, 1965; THOMPSON, 1967; HREBINIAK; JOYCE, 1985; MAHONEY, 1993), e a integração conceitual entre estratégia e ambiente foi apresentada na década de 1980 (BOURGEOIS, 1980). Esse debate reconhece que o ambiente exerce influência sobre as ações estratégicas da organização, exigindo 
dela adaptação estratégica (CUNHA, 1996; CARVALHO; ROSSETTO; VIANNA, 2009). Por conseguinte, para analisar e procurar compreender as mudanças e adaptações estratégicas de uma organização é essencial observar o caráter dinâmico e flexível do ambiente externo e, principalmente, enfatizar a compreensão das incongruências ambientais que interagem com a estrutura interna da organização (MILES, 1980). Alperstedt, Martignago e Fiates (2006) consideram o ambiente como fator determinante do sucesso e da sobrevivência organizacional, retirando da organização a capacidade de escolha estratégica.

O debate entre os estudiosos do processo de adaptação estratégica focam dois aspectos. Um é a visão determinista, que vê o ambiente externo como elemento principal na definição das estratégias organizacionais; outro é a visão voluntarista ou da escolha estratégica, que defende a organização com capacidade de manipular o ambiente em função de suas capacidades materiais e organizacionais (ROSSETTO, 1998).

Considerando-se a busca das organizações pela sobrevivência frente à dinâmica ambiental, este estudo propõe-se a descrever e analisar o processo de mudança e adaptação estratégica de uma empresa distribuidora de gás liquefeito de petróleo (GLP) no Brasil, com vistas a recolocar no debate teórico a influência do determinismo ambiental e a capacidade de escolha estratégica em ambientes competitivos. Para tanto, o estudo partiu do seguinte problema de pesquisa: como ocorreu o processo de mudança e adaptação estratégica em uma empresa distribuidora de gás liquefeito de petróleo, no período de 1993 a 2013, e qual a influência do determinismo ambiental e a capacidade de escolha estratégic?

Este artigo estrutura-se em quatro seções, além desta introdução. A primeira apresenta a fundamentação teórica sobre processo de mudança estratégica em relação com determinismo versus voluntarismo ambiental. $\mathrm{Na}$ segunda parte, apresentam-se os procedimentos metodológicos que orientaram a investigação empírica. Por fim, na terceira e quarta partes, apresentam-se os resultados e as considerações finais, respectivamente.

\section{Referencial teórico}

\section{$2.1 \mathrm{O}$ processo de mudança estratégica}

As organizações, indiferente do segmento de atuação, precisam estar preparadas para o dinamismo do mercado a fim de minimizarem os impactos negativos oriundos das incertezas mercadológicas que põem em risco a sobrevivência organizacional. 
A capacidade de mensurar as incertezas ambientais é foco de diversos estudos na literatura sobre estratégia, dentre esses destacam-se os autores: Duncan (1972), Aldrich e Pfeffer (1976), Hrebiniak e Joyce (1985), Whittington (1988), Conant, Mokwa e Varadarajan (1990), Rossetto (1998), Sausen, Treter e Wbatuba (2004), Carvalho, Rossetto e Vianna (2009), Rossetto, Lazzaretti e Vargas (2012).

O processo de adaptação estratégica refere-se a um período adaptativo que ocorre nas organizações quando elas se moldam ao ambiente em que estão inseridas, com o objetivo centrado na manutenção de sua competitividade em função das novas exigências ambientais. As novas necessidades propostas pelo ambiente proporcionam de forma compulsória a necessidade de mudanças estratégicas que tem como objetivo principal responder às novas pressões competitivas externas e ou internamente.

Os estudos de Ceretta e Sausen (2010) afirmam que a estratégia pode ser considerada a força invisível das organizações contemporâneas, usada para adaptar-se e gerenciar as mudanças ambientais. A compatibilização de estratégias deve ser feita de maneira que se possa usufruir de todas as oportunidades possíveis, utilizando a estratégia adequada, no momento adequado.

No entendimento de Pettigrew (1987), o ponto de partida para a análise da mudança estratégica é a perspectiva de que a formulação do conteúdo, de qualquer ação estratégica nova, interfere na gestão do seu contexto e processo. Para 0 autor, o contexto externo refere-se aos ambientes social, econômico, político e competitivo, e o contexto interno corresponde à estrutura, à cultura corporativa e ao contexto político. O conteúdo, na perspectiva de Pettigrew (1987), corresponde às áreas particulares de transformação que estão sendo examinadas, na medida em que o processo de mudança refere-se às ações, reações e interações adotadas pelos agentes. Além disso, uma característica a ser ressaltada no processo de mudança estratégica é que uma decisão estratégica dificilmente pode ser explicada sem se conhecer previamente as decisões e os eventos ocorridos (ROSSETTO; CUNHA; ORSSATTO, 1997). Assim, na maioria das vezes, as mudanças são percebidas quando o ambiente organizacional já está configurado em novo formato e com nova dinâmica, exigindo apenas uma atitude passiva da organização. Ações proativas, no entanto, dependem da competência do gestor.

Na perspectiva de Rossetto e Rossetto (2005), a adaptação organizacional refere-se à habilidade dos administradores de reconhecer, interpretar e implementar estratégias de acordo com necessidades e mudanças percebidas em seu ambiente, de forma a assegurar suas vantagens competitivas. A partir da análise longitudinal, é possível descrever o processo de mudança estratégica, resgatando a frequência do processo de mudança da organização (ROSSETTO; CUNHA; ORSSATTO, 1997). 
Contudo, Rossetto e Rossetto (2005) afirmam que o estudo de adaptação estratégica envolve visões deterministas do ambiente organizacional e voluntarista da escolha estratégica pelos tomadores de decisão organizacional. Os pressupostos deterministas estão centrados na supremacia ambiental, ou seja, o ambiente é elemento fundamental para as ações estratégicas. Enquanto que na visão voluntarista, a organização exerce poder de modificar o ambiente por intermédio de seus principais agentes.

\subsection{Determinismo e voluntarismo ambiental}

Muitas abordagens teóricas procuram compreender e explicar as mudanças pelas quais as organizações passam em sua história. A concepção das organizações como sistemas abertos considera que as organizações e seus ambientes externos são partes de um sistema mais amplo que interagem continuamente. A organização troca recursos com o ambiente, garantindo sua sobrevivência, e se modifica para se adaptar às contingências ambientais que lhe facultam acesso a esses recursos (BERTALANFFY, 1968).

Astley e Van de Ven (1983) afirmam que na orientação determinista, as ações estratégicas são definidas pelas restrições ambientais e a elas reagem no intuito de proporcionar a manutenção da sobrevivência organizacional frente às turbulências ambientais percebidas pelos gestores. A perspectiva da seleção natural é originária de modelos darwinianos da evolução das espécies, representado pela ecologia das populações (HANNAN; FREEMAN, 1977).

O modelo da ecologia das populações fundamenta-se no questionamento teórico do pressuposto da capacidade de adaptação da organização ao seu ambiente, assumido pelas teorias da contingência estrutural e neoclássica. As firmas são encaradas como "atores racionais limitados", com alto grau de inércia organizacional (estrutural), que interagem em um ambiente competitivo (HANNAN; FREEMAN, 1989, p. 172). Essa interação determina variações ambientais que impõem restrições à população das firmas, selecionando aquelas que estão mais aptas a sobreviver e eliminando naturalmente os mais fracos (HANNAN; FREEMAN, 1977, 1989; BAUM, 2001). Nessa abordagem, a organização tem pouca influência em seu destino, tendo o ambiente um caráter também determinista.

Alguns teóricos representantes do determinismo ambiental, como Hannan e Freeman (1977) e Pfeffer e Salancik, (1978), contextualizam a adaptação como o processo pelo qual as organizações se adaptam conforme as contingências ambientais. Nessa visão, o papel atribuído aos gestores fica restrito à adequação da 
estrutura às condições variáveis do ambiente. A perspectiva da ecologia das populações acredita na existência de limites à ação ou escolha da organização em relação ao seu ambiente.

A teoria institucional, por sua vez, originária de estudos sociológicos, entende que as organizações sofrem pressões de grupos, normas sociais, tanto externas quanto internas (ZUCKER, 1977). Selznick (1955) complementa essa perspectiva, afirmando que a tomada de decisão é gerencial e influenciada por agentes supraorganizacionais (como associações de classe ou órgãos governamentais) de um ambiente. A partir da luta pelo poder e da formação de alianças, determina-se a formação de uma matriz institucional (regras e legislação formal) que passa a vigorar no ambiente. Dessa forma, cria-se uma pressão para adaptação contínua das organizações do ambiente às forças institucionais dominantes. Essa abordagem, conhecida como teoria institucional, é, portanto, determinista com relação à influência do ambiente sobre a organização.

De acordo com DiMaggio e Powell (1983), no momento em que organizações diferentes estão estruturadas em um mesmo segmento, forças emergem orientando-as a se tornarem mais similares. Essas forças agem sob a forma de mecanismos isomórficos, sejam eles normativos, miméticos ou coercitivos. As implicações dessas teorias institucionais para a adaptação estratégica são que a sobrevivência organizacional está vinculada ao alinhamento dos seus valores e práticas com as normas institucionalizadas no campo.

Meyer e Rowan (1977) buscam sua base teórica a partir do trabalho institucional de Selznick (1955), na perspectiva conhecida como neoinstitucional. Segundo os autores, o ambiente é concebido a partir de dois tipos de recursos: econômicos ou técnicos e institucionais. Os recursos econômicos são concretos, já os recursos institucionais são nominalistas, incluindo reputação, liderança, prestígio e eficiência.

Clegg (1990) enfatiza a principal diferença da abordagem neoinstitucional com a perspectiva do institucionalismo de Selznick, os atores organizacionais estão envolvidos em processos cognitivos de construção da realidade. Assume-se aqui a "sociologia do conhecimento", de Berger e Luckmann (1966), com seu paradigma cognitivista de que o processo de interações entre os indivíduos constrói e legitima o conhecimento e as normas de conduta socialmente aceitas. Nesse sentido, a institucionalização é o processo pelo qual os atores individuais disseminam o conhecimento validado (ZUCKER, 1977). DiMaggio e Powell (1983) argumentam que o isomorfismo é a razão dominante pela qual as organizações assumem determinadas formas, conceituando três mecanismos por meio dos quais a mudança isomórfica 
institucional ocorre, cada um com seus próprios antecedentes: 1) isomorfismo coercivo; 2) isomorfismo mimético; e, 3) isomorfismo normativo.

Os modelos que defendem a escolha estratégica, como construção, sustentação e mudança, a partir do significado que os atores organizacionais atribuem a cada situação, são chamados voluntarismos (ASTLEY; VAN DE VEN, 1983).

Diferentemente da visão determinista, a visão voluntarista é constituída por um conjunto de perspectivas que versam acerca dos padrões de mudança nas organizações, como consequências da base cognitiva dos agentes frente às mudanças ambientais. A partir da utilização dessa abordagem, é possível compartilhar a ideia de que a escolha estratégica é possível (CUNHA, 1996).

Teóricos da administração estratégica, como Aldrich e Pfeffer (1976) e Pfeffer e Salancik (1978) e Astley e Van de Ven (1983), entendem que as organizações são dependentes do que está em seu ambiente de negócios, cujos debates consolidam uma teoria (teoria da dependência de recursos) com foco na análise das decisões e das ações das organizações sobre o ambiente. O pressuposto teórico dessa abordagem é de que as organizações são dependentes de recursos fornecidos por outras organizações, criando-se assim uma relação interorganizacional no ambiente de atuação para obter-se recursos estratégicos (THOMPSON, 1967; PFEFFER; SALANCIK, 1978).

Assim, a teoria da dependência de recursos sustenta o argumento de que as organizações são ativas no ambiente de negócios, delineando uma atitude não determinista, e sim voluntarista (BOURGEOIS, 1984; CHILD, 1992) pelas escolhas que faz. Consideram-se como exemplos de escolha estratégica as formas cooperativas, as fusões/alianças/parcerias que estabelecem, e a movimentação de pessoal entre empresas (PFEFFER, 1972; ALDRICH; PFEFFER, 1976). Bataglia et al. (2009) também consideram que essa abordagem assume um caráter voluntarista, ou seja, de que a organização é percebida como um conjunto de seres humanos dotados de autonomia, com visão estratégica sobre as consequências de suas ações e que constroem o ambiente externo.

A partir dessa abordagem teórica, a escolha estratégica tem sido observada como possível nas situações de tomada de decisão em que o formato das estruturas pode ser escolhido, formado mais em função de considerações políticas do que técnicas, como argumenta Child (1972). Essa perspectiva teórica versa sobre o papel do gestor, considerando-o proativo, e sua base cognitiva é responsável pelo significado dos eventos ambientais. Dessa forma, pode-se afirmar que na escolha estratégica o ambiente subjetivo se sobrepõe ao objetivo, calcado na cognição dos tomadores de decisão. 


\subsection{A visão interativa do determinismo versus voluntarismo}

Com o foco centrado nas discussões teóricas, levantadas principalmente por Astley e Van de Ven (1983), Hrerbiniak e Joyce (1985) apresentam uma nova perspectiva de análise para o determinismo e a escolha estratégica (voluntarismo), considerando-as variáveis independentes entre si, e que a interação entre ambas é importante para explicar o comportamento gerencial e o processo de adaptação estratégica nos diferentes períodos históricos da organização.

O modelo apresentado por Hrerbiniak e Joyce (1985), conforme Figura 1, propõe um sistema de quadrantes no qual são criadas dimensões independentes, uma de determinismo ambiental e outra de escolha estratégica.

Figura 1 - Grau de determinismo ambiental e capacidade de escolha estratégica

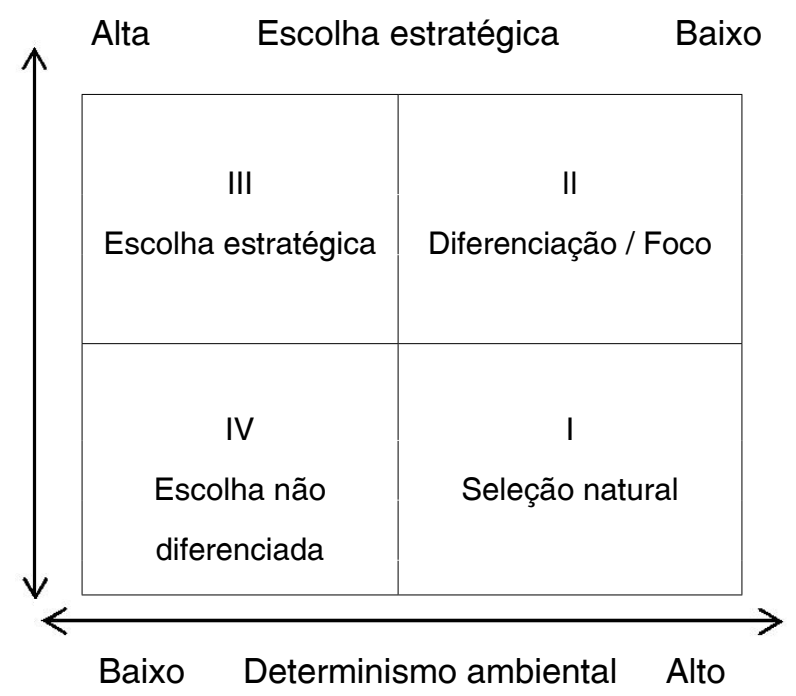

Fonte: adaptado de Hrebiniak e Joyce (1985).

O quadrante I apresenta elevado determinismo ambiental e baixa escolha estratégica, denominado seleção natural. Organizações com ajuste apropriado ao ambiente são selecionadas para sobreviver, porém, as que não estão de acordo com os padrões definidos pelo ambiente são eliminadas (ALDRICH; PFEFFER, 1976 apud HALL, 1984). Já no quadrante III há elevada presença de escolha estratégica e baixo determinismo ambiental. 
O modelo proposto por Hrerbiniak e Joyce (1985) contribui ao acrescentar os quadrantes II e IV. No quadrante II, tanto a escolha quanto o determinismo do ambiente são elevados, caracterizando ambiente de turbulência. O quadrante IV é caracterizado por baixa escolha estratégica e baixo determinismo ambiental. Embora o ambiente ofereça poucas restrições, tampouco a organização exerce opções de escolha. As firmas classificadas no quadrante IV apresentam comportamentos estratégicos denominados reativos, segundo Miles e Snow (1978), e tendem a substituir a racionalidade pela irracionalidade como base para a tomada de decisão.

A interdependência e as interações entre escolha estratégica e determinismo ambiental definem a adaptação. Cada um é insuficiente e ambos são necessários para uma explicação satisfatória da adaptação estratégica. Considera-se adaptação um processo dinâmico, resultado da força e do tipo de poder ou de dependência entre organização e ambiente. A escolha estratégica e o determinismo ambiental fornecem impulsos para a mudança. Cada um é causa e consequência do outro no processo de adaptação. A discussão sugere complexidade e interdependência das variáveis e dos processos de decisão, como uma função tanto de escolha quanto de determinismo (HREBINIAK; JOYCE, 1985).

\section{Metodologia}

O presente estudo configura-se como uma pesquisa exploratória e descritiva, com design de estudo de caso e abordagem qualitativa dos dados. Utilizou-se o modo de análise longitudinal e histórico, proposto por Pettigrew (1987), que aborda as dimensões de contexto, conteúdo e processos, os procedimentos da direct research, de Mintzberg e McHugh (1985), e o modelo de adaptação estratégica de Hrebiniak e Joyce (1985), para verificar o grau de determinismo ambiental e a capacidade de escolha estratégica.

Essa opção metodológica é recomendada por Mintzberg (1977) na construção de modelos de análise de mudanças organizacionais, estabelecidos com base em dados e observações de fatos e desenvolvidos de forma indutiva com base na investigação sistemática do comportamento da empresa selecionada de forma intencional, no caso, uma empresa distribuidora de gás liquefeito de petróleo.

Pettigrew (1987) sugere que, para se realizar um estudo sobre mudança organizacional, é necessária uma forma de pesquisa com caráter histórico, contextualizador e processual. Dessa forma, para a realização deste estudo, utilizou-se a pesquisa descritiva, tendo em vista o conteúdo, o processo e o contexto da mudança. 
No que se refere à dimensão longitudinal do estudo, a pesquisa é orientada pelo paradigma interpretativista, que explica seu caráter temporal diante do período histórico escolhido de um decêndio, delimitado entre 1993 e 2013 . O recorte temporal foi realizado pelo critério de acessibilidade aos dados empíricos e que representam um novo período histórico da dinâmica mercadológica do Brasil, em razão da abertura dos mercados ocorrida no início dos anos 1990 (GIAMBIAGI; MOREIRA, 1999). No presente estudo, foi utilizada como técnica de coleta de dados a entrevista em profundidade com um gestor da empresa, que relatou os principais eventos ocorridos no período objeto deste estudo.

A técnica para a coleta dos dados foi a entrevista semiestruturada, que, para a pesquisa qualitativa, é um dos principais meios de coleta de dados, pois, ao mesmo tempo que valoriza a presença do gestor, oferece todas as perspectivas possíveis para que o informante alcance a liberdade e a espontaneidade necessárias, enriquecendo a investigação (TRIVIÑNOS, 1987). Foi realizada uma entrevista com o gestor da empresa objeto de estudo, com duração de duas horas, com vistas a identificar os episódios que marcaram as estratégias e as mudanças organizacionais no período de 1993 a 2013. Tais eventos foram organizados na linha do tempo e identificados em três períodos: (i) gestão operacional/financeira; (ii) mudanças estruturais, culturais, organizacionais e estratégicas; (iii) gestão de resultados.

Este estudo também utilizou a pesquisa documental para coletar informações complementares em documentos, como o contrato social e a página eletrônica oficial da empresa. Para complementar, a pesquisa bibliográfica em livros e periódicos foi realizada para compreender as formas associativas.

A partir dos procedimentos metodológicos da direct research, método descrito por Mintzberg e McHugh (1983), definiram-se as seguintes fases de investigação:

a) realização de entrevistas, pesquisas bibliográfica e documental, de maneira simultânea, sendo que a coleta e a análise de dados formaram um processo interativo, em que são identificados processos emergentes e categorias conceituais;

b) elaboração de uma lista de eventos considerados importantes em relação à estratégia, a partir de informações e dados retirados da entrevista e da análise documental;

c) inferência dos períodos de mudança e das estratégias, com base na interpretação do entrevistado e do pesquisador;

d) caracterização das condições do contexto sociopolítico do estado e do país que influenciaram as decisões e ações da gestão da empresa, a partir da percepção do entrevistado e da pesquisa documental e bibliográfica;

e) análise teórica de cada período estratégico. 
Conhecer o histórico permite traçar uma linha do tempo, na qual escolhas e decisões tomadas refletem os acontecimentos presentes e futuros. O estudo da adaptação estratégica revelado por Petigrew diz que se deve perceber a continuidade e a mudança, os padrões e as idiossincrasias, as ações de indivíduos e grupos e os processos de estruturação, pois em muitos casos as "pesquisas sobre mudanças organizacionais são a histórica, a processual e a contextual” (1987, p. 655).

Para proporcionar legitimidade à pesquisa de adaptação estratégica, buscou-se conhecer os eventos históricos que serviram de base para a concepção do estudo sobre a influência do determinismo ambiental no processo de adaptação e mudança estratégica em uma empresa distribuidora de gás liquefeito de petróleo, no período de 1993 até 2013 . Os dados foram coletados em entrevista com o gestor da empresa, que está no segmento há 24 anos e vivenciou todas as fases da organização, no período escolhido para análise. Inicialmente, as entrevistas foram gravadas e, após, transcritas para a construção de um quadro resumo, que identifica os períodos estratégicos e aponta para os principais eventos críticos relatados pelo entrevistado.

Dessa forma, os dados serão apesentados no próximo capítulo, divididos em três períodos estratégicos, denominados: gestão operacional e financeira, mudanças estruturais, cultura organizacional e estratégica e gestão de resultado.

\section{Apresentação e análise dos dados}

A empresa investigada passou por três períodos estratégicos, denominados: (i) gestão operacional/financeira: de 1993 a 2000; (ii) mudanças estruturais, cultura organizacional e estratégica, de 2004 a 2010; (iii) gestão de resultados, de 2011 a 2013. Esses períodos estratégicos são apresentados a seguir.

\subsection{Período estratégico (i): gestão operacional/financeira (1993 a 2000)}

O primeiro período estratégico identificado na organização foi marcado por grandes perdas financeiras por conta de ações socioeconômicas no cenário nacional, tendo como principal consequência a ação da direção da empresa em terceirizar a logística e a distribuição. Esse período corresponde à análise entre 1993 e 2000.

O cenário econômico e político do país em 1990 passava por mudanças, marcado principalmente pela política econômica dos presidentes da República Fenando Collor de Mello e Fernando Henrique Cardoso. Dando prosseguimento aos processos 
de abertura econômica e de integração externa iniciados no governo Collor, Fernando Henrique Cardoso revogou todas as medidas de favorecimento dos capitais nacionais em relação aos estrangeiros, privatizou a produção estatal, alterando o relacionamento entre os modos de produção. A ação governamental ocasionou uma ruptura no modo capitalista de produção, que deixou de ser tutelado pelo Estado e passou a integrar o grande capital global, controlado por residentes nos chamados países centrais, foi sendo sistematicamente fomentado, caracterizado principalmente por fusões e aquisições de empresas nacionais por organizações estrangeiras, proporcionando, dessa forma, o fomento da competitividade (PINHEIRO; GIAMBIAGI; GOSTKORZEWICZ, 1999).

Até 1990, o governo protegia o segmento gás liquefeito de petróleo, com ações de estabilidade de preços. A partir do governo do presidente Fernando Henrique Cardoso, o mercado é liberado para a livre concorrência, e as empresas passam a conviver com problemas financeiros e com a entrada de empresas estrangeiras no país com recursos para competir nesse mercado. As consequências dessas ações são identificadas na empresa, objeto de estudo pela terceirização de atividades essências e pela venda de uma parcela de suas ações.

Dessa forma, o primeiro período estratégico é classificado pela perspectiva da seleção natural, referenciada pelo alto grau de determinismo ambiental e pela baixa capacidade de escolha estratégica. Na perspectiva de Hrebiniak e Joyce (1985), são empresas com sobrevivência ameaçada.

\subsection{Período estratégico (ii): mudanças estruturais, cultura organizacional e estratégica (2004 a 2010)}

Em 2004, é oficializada a venda total das ações da empresa. Esse período foi marcado pelas mudanças estruturais, culturais e estratégicas. A mudança na estrutura societária da empresa ocasionou diferenças significativas na estrutura operacional, administrativa, financeira e comercial da empresa.

Nesse período, a empresa optou pela busca de um nicho de mercado mais rentável, denominado pela organização de venda direta, que representa a venda direta a grandes consumidores, como condomínios, indústrias e agronegócios. Essa ação deliberada da empresa demostra o estilo de gestão que assumiu o controle societário, pois a ação fica marcada pela habilidade de escolha estratégica dos tomadores de decisão a fim de manter a capacidade de retorno sobre o investimento mais aproximada. 
O período é classificado por diferenciação e foco, cujo grau de determinismo ambiental e capacidade de escolha estratégica são altos. Essa classificação implica um contexto turbulento de adaptação, embora as organizações identificadas nesse perfil sejam capazes de seguir estratégias de diferenciação e foco, escolhendo nichos de mercado ou segmentos dentro dos limites estabelecidos pelo ambiente.

\subsection{Período estratégico (iii): gestão de resultado (2011 a 2013)}

No terceiro período estratégico, marcado pelas mudanças estratégicas ocorridas entre os anos 2011 e 2013, constatou-se a substituição da razão social da empresa e a tentativa de mudar a cultura organizacional por um modelo de gestão de resultados. O que determinou sua identificação foi o conjunto de ações implementado, centrado na eficiência operacional e na busca por maior rentabilidade nas operações. A empresa tem sua estratégia de vendas focada nas atividades de varejo, com venda direta ao consumidor, a fim de obter maior rentabilidade.

Nesse período observou-se que a empresa adota uma postura de alta performance, dando continuidade a ações em nichos de mercado mais rentáveis bem como qualificando sua equipe comercial, financeira e estrutural, seus investimentos foram em produtividade e eficiência operacional e tecnológica.

O terceiro período estratégico (2011 a 2013) é denominado como a busca por resultado. A interdependência e as interações entre escolha estratégica e determinismo ambiental definem a adaptação, ou seja, cada um é insuficiente e ambos são necessários para uma explicação satisfatória da adaptação estratégica. Esse período estratégico, analisado pelo modelo analítico proposto por Hrebiniak e Joyce (1985), é de alta influência ambiental e de altas escolhas estratégicas.

No Quadro 1, é possível visualizar os principais eventos ocorridos na empresa, nos diferentes períodos estratégicos, bem como a tipologia de adaptação estratégica. 


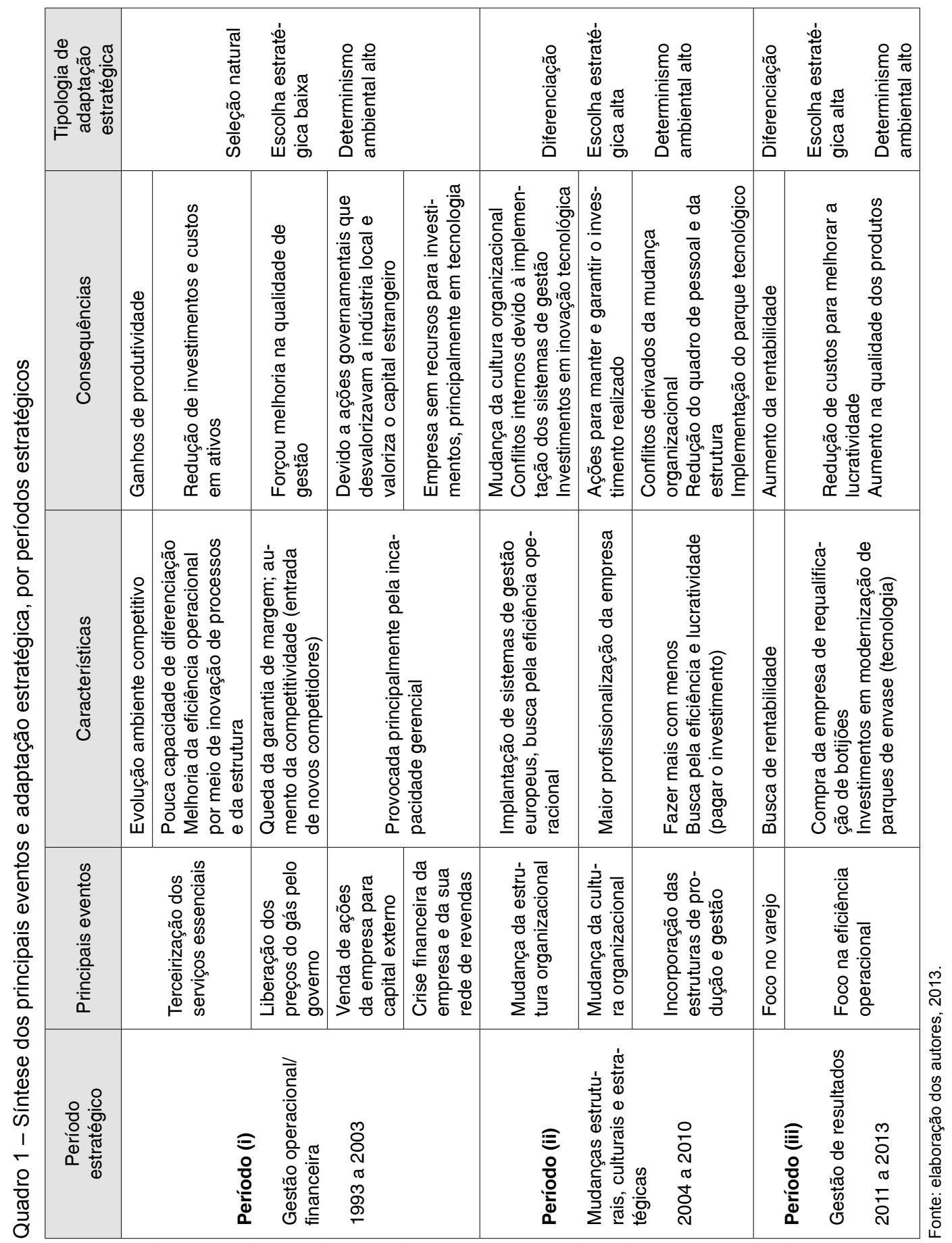

Teoria e Evidência Econômica - Ano 21, n. 44, p. 165-185, jan./jun. 2015 
Os dados revelados pelo quadro síntese mostram que as tipologias de adaptação estratégica, a partir do modelo proposto por Hrebiniak e Joyce (1985) para verificar o grau de determinismo ambiental e a capacidade de escolha estratégica, indicam que o primeiro período estratégico, denominado gestão operacional financeira (1993 a 2003), é classificado de seleção natural, ou seja, nesse período a escolha estratégica é baixa e o determinismo ambiental apresenta-se alto. No segundo período, denominado mudanças estruturais, culturais e estratégicas (2004 a 2010), a tipologia identificada foi de diferenciação, ou seja, tanto a escolha estratégica quanto o determinismo ambiental são altos. E, por fim, o período denominado gestão de resultados (2011 a 2013) permanece a tipologia de diferenciação, em que tanto as escolhas quanto o determinismo ambiental são altos.

Em uma análise mais consolidada do processo de mudança e da adaptação estratégica da empresa objeto de estudo, pode-se afirmar que, embora o determinismo ambiental tenha sido decisivo no quadro do reposicionamento estratégico para melhorar seus níveis de competitividade, a empresa conseguiu fazer escolhas estratégicas, haja vista que, nos dois últimos períodos de mudança, o enquadramento ficou na tipologia de diferenciação, que mescla a pressão do ambiente externo com a capacidade de exercer escolhas.

Entretanto, em todo o período de análise (1993-2013), as contingências ambientais tiveram uma influência decisiva, por tratar-se de um segmento da atividade econômica regulamentado pelo governo, que faz com que as empresas distribuidoras de gás liquefeito de petróleo promovam adaptações estratégicas condicionadas pelo ambiente institucional (órgão regulador).

\section{Considerações finais}

Com base na análise consolidada dos dados empíricos desta pesquisa, os resultados remetem para um novo debate acerca da identificação da influência do determinismo ambiental no processo de adaptação e mudança estratégica em uma empresa distribuidora de gás liquefeito de petróleo.

Nesse sentido, conclui-se que, embora o determinismo ambiental tenha sido decisivo no quadro do reposicionamento estratégico da para melhorar seus níveis de competitividade, a empresa conseguiu fazer escolhas estratégicas, pois, nos dois últimos períodos, o enquadramento ficou na tipologia de diferenciação. Destaca-se que, em todo o período de análise (1993-2013), as contingências ambientais tiveram uma influência decisiva, por tratar-se de um segmento de atividade econômica regulamentado pelo governo, que faz com que as empresas distribuidoras de gás 
liquefeito de petróleo promovam adaptações estratégicas condicionadas pelo ambiente institucional (órgão regulador).

Não obstante, o caso estudado revela que essa forte regulamentação não compromete a capacidade de escolha estratégica das organizações. Nesse caso, as escolhas estratégicas mostraram-se decisivas para a sobrevivência e busca da competitividade organizacional. Os investimentos em tecnologia de envasamento de gás mostraram-se estratégia importante no reposicionamento estratégico da empresa, como também a estratégia de qualificação do sistema de gestão, na linha da implementação de uma gestão por resultado, focada na eficiência operacional da empresa, foram escolhas corretas e decisivas em termos de performance organizacional.

Diante disso, afirma-se que, considerando este um estudo exploratório e que não permite generalização por contemplar um design de pesquisa de estudo de caso, afirma-se que a influência do determinismo ambiental nas ações estratégicas não compromete a capacidade de escolha estratégica.

Para a continuidade das pesquisas, sugere-se um estudo que permita uma visão mais ampla do processo de reposicionamento estratégico da empresa para melhor competir no mercado, incluindo a sua rede de distribuição, que se constitui um canal importante para que o produto chegue em boas condições ao consumidor final. Identificar as estratégias utilizadas na rede de distribuidores e o impacto do determinismo ambiental nesse tipo de segmento, incluindo a rede terceirizada, passa a ser importante para analisar o desempenho da empresa que opera nesse setor, fortemente regulamentado. 


\title{
The influence of environmental determinism in process of change adaptation strategically a company that is liquefied petroleum gas distributor
}

\begin{abstract}
This article presents the methodology and results of a study that aims to describe the process of adaptation and strategic shift. Therefore, we analyzed the influence of environmental determinism and the ability of strategic choice in a company that is liquefied petroleum gas distributor, in the 1993-2013 period. It is a unique case study and a qualitative data approach, with historical and longitudinal analysis. The results indicate three strategic periods and confirmed that, although the environmental determinism had been decisive in its strategic repositioning, the company managed to exercise capacity of strategic choice in the three indicated periods.
\end{abstract}

Keywords: Strategic shift process. Strategic adjustment. Environmental determinism.

\section{La influencia del determinismo ambiental en el proceso de adaptación y cambio estratégico en una empresa distribuidora de gas licuefacto de petróleo}

\section{Resumen}

El presente artículo presenta la metodología y los resultados de un estudio cuyo objetivo describe el proceso de adaptación y cambio estratégico, por consiguiente, se analizó la influencia del determinismo ambiental y la capacidad de elección estratégica en una empresa distribuidora de gas licuefacto de petróleo durante el período de 1993 a 2013. Se trata de un estudio de caso único y de abordaje cualitativo de datos con análisis histórico y longitudinal. Los resultados indicaron tres periodos estratégicos y confirmaron que a pesar de que el determinismo ambiental fuese decisivo en el reposicionamiento estratégico de la empresa, la misma consiguió ejercer capacidad de elección estratégica en los tres períodos identificados.

Palabras clave: Proceso de cambio estratégico. Ajuste estratégico. Determinismo ambiental. 


\section{Referências}

ALDRICH, H. E.; PFEFFER, J. Organizations and environments. New York: Ithaca, New York State School of Industrial and Labor Relations, Cornell University, 1976.

ALPERSTEDT, G. D.; MARTIGNAGO, G.; FIATES, G. G. S. O processo de adaptação estratégica de uma instituição de ensino superior sob a ótica da teoria institucional. Revista de Ciências da Administração, Florianópolis, v. 8, n. 15, p. 114-137, 2006.

ASTLEY, W. G.; VAN DE VEN, A. H. Central perspectives and debates in organization theory. $A S Q$, v. 28, n. 2, p. 245, 1983.

BANDEIRA-DE-MELO, R.; CUNHA, C. Administrando o risco: uma teoria substantiva da adaptação estratégica de pequenas empresas a ambientes turbulentos e com forte influência governamental. Revista de Administração Contemporânea, v. 8, 2004. Edição especial.

BAUM, J. A. C. Ecologia organizacional. In: CLEGG, S. R.; HARDY, C.; NORD, W. R. (Org.). Handbook de Estudos Organizacionais. São Paulo: Atlas, 2001.

BERGER, P. L.; LUCKMAN, T. The social construction of reality. New York: Doubleday \& Company, 1966.

BERNARDES, M. E. B.; SÁ, F. S. Voluntarismo e determinismo em implementação de estratégias coletivas de $P M E$ : uma análise de dois processos em arranjos produtivos moveleiros. 2009. Disponível em: <http://www.anpad.org.br/diversos/trabalhos/3Es/3es_2009/3ES336.pdf>. Acesso em: 2 jan. 2015.

BERTALANFFY, L. V. General systems theory. New York: George Braziller, 1968.

BOURGEOIS, L. J. Strategy and environment: a conceptual integration. The Academy of Management Review, New York, v. 5, n. 1, p. 25-39, 1980.

BOURGEOIS, L. J. Strategic Management and Determinism. AMR, v. 9, p. 586-596, 1984.

CARVALHO, C. E.; ROSSETTO, C. R.; VIANNA, S. L. G. Adaptação estratégica: o caso da Berlanda Móveis e Eletrodomésticos. In: ENCONTRO DE ESTUDOS EM ESTRATÉGIA, 4, 2009, Anais... Rio de Janeiro: Anpad, 2009.

CERETTA, S.; SAUSEN, J. O. Mudança e adaptação organizacional: um estudo do reposicionamento estratégico com vistas à autossustentação financeira de uma escola de formação profissional. In: ENCONTRO DA ANPAD, 34, 2010, Rio de Janeiro. Anais... Rio de Janeiro: Anpad, 2010.

CHILD, J. Organizational structure environment performance: the role of strategic choice. Sociology, Londres, v. 6, p. 1-22, 1972.

CLEGG, S. R. Modern organizations: organization studies in the postmodern world. London: Sage, 1990.

CONANT, J. S.; MOKWA, M. P.; VARADARAJAN, P. R. Strategic types, distinctive marketing competencies and organizational performance: a multiple measures-based study. Strategic Management Journal, Chicago, v. 11, p. 365-383, p. 365-383, 1990.

CUNHA, C. J. C. A. Adaptação estratégica em ambiente turbulento. 1996. Tese (Concurso de professor titular) - Programa de Pós-Graduação em Engenharia de Produção - Departamento de Engenharia de Produção e Sistemas, UFSC, Florianópolis, 1996. 
DIMAGGIO, P. J.; POWELL, W. W. The iron cage revisited: institutional isomorphism and collective rationality in organizational fields. In: POWELL, W. W.; DIMAGGIO, P. J. (Ed.). The new institutionalism in organization analysis. Chicago: University of Chicago, 1983.

DIVERIO, T. S. M.; OLIVEIRA, L. C. P. Mudança estratégica organizacional: um estudo de caso na cooperativa castilhense. In: ENCONTRO NACIONAL DE ENGENHARIA DE PRODUÇÃO, 26, 2006, Fortaleza. Anais... Fortaleza-Ceará: Enegep, 2006.

DUNCAN, R. B. Characteristics of organizational environments and perceived environmental uncertainty. Administrative Science Quarterly, Nova York, v. 17, p. 313-327, 1972.

EMERY, F.; TRIST, E. The causal texture of organizational environments. Human Relations, London, v. 28, p. 21-33, 1965.

GIAMBIAGI, F.; MOREIRA, M. M. (Org.). A economia brasileira nos anos 90. Rio de Janeiro: BNDES, 1999. p. 11-41.

HALL, R. H. Organizações, estrutura e processos. Rio de Janeiro: Prentice-Hall, 1984.

HANNAN, M. T.; FREEMAN, J. Organizational ecology. Cambridge: Harvard Business, 1989.

. The population ecology of organizations. American Journal of Sociology, Chicago, v. 82, p. 929-964, 1977.

HREBINIAK, L. G.; JOYCE, W. F. Organizational adaptation: strategic choice and environmental determinism. Administrative Science Quarterly, Nova York, v. 30, p. 336-349, 1985.

LOPES, P. C. B.; STADLER, C. C.; KOVALESKI, L. J. L. Gestão da mudança organizacional. Revista Publicatio: Ciências Humanas, Linguística, Letras e Artes, Ponta Grossa, v. 11, n. 1, p. 51-57, jun. 2003.

MAHONEY, J. T. Strategic management and determinism: sustaining the conversation. Journal of Management Studies, Oxford, v. 30, n. 1, p. 173-191, 1993.

MEYER, J. W.; ROWAN, B. Institutional organizations: formal structure as myth and ceremony. American Journal of Sociology, Chicago, v. 83, p. 340-363, 1977.

MILES, R. H. Macro organizational behavior. Illinois: Scott Foresman \& Cia., 1980.

MILES, R. E.; SNOW, C. C. Organizational strategy, structure and process. New York: McGraw Hill, 1978.

MINTZBERG, H. A criação artesanal da estratégia. In: PORTER, M. E.; MONTGOMERY, C. A. Estratégia: a busca da vantagem competitiva. Rio de Janeiro: Campus, 1998.

MINTZBERG, H. Power in and around organizations. New York: Prentice Hall, 1983.

MINTZBERG, H. Strategy formulation as a historical process. International Studies of Management and Organization, New York, v. 7, n. 2, p. 28-40, summer 1977.

MINTZBERG, H.; MCHUGH, A. Strategic formulation in an adhocracy. Administrative Science Quarterly, Nova York, v. 30, p. 160-197, 1985.

MINTZBERG, H.; AHLSTRAND, B.; LAMPEL, J. Safari de estratégia: um roteiro pela selva do planejamento estratégico. Porto Alegre: Bookman, 2000.

PETTIGREW, A. Contex and action in the transformation of the firm. Journal of Management Studies, Oxford, v. 24, n. 6, p. 649-670, 1987. 
PFEFFER, J. Size and composition of corporate boards of directors: the organization and its environment. Administrative Science Quarterly, Nova York, v. 17, p. 218-228, 1972.

PFEFFER, J.; SALANCIK, G. R. The external control of organizations: a resource dependence perspective. New York: Harper \& Roll, 1978.

PINHEIRO, A. C.; GIAMBIAGI, F.; GOSTKORZEWICZ, J. O desempenho macroeconômico do Brasil nos anos 90. In: GIAMBIAGI, F.; MOREIRA, M. M. (Org.). A economia brasileira nos anos 90. Rio de Janeiro: BNDES, 1999. p. 11-41. Capítulo 1.

QUERINO, M. P.; MORAES, M. O processo de adaptação estratégica da escola superior de administração e gerência: da concepção à percepção de seus gestores estratégicos. Revista de Administração, Contabilidade e Economia, Joaçaba, v. 13, n. 1, p. 181-218, 2014.

RINGON, C. M.; OLIVEIRA, L. C. P. Mudança estratégica: o caso do setor alcooleiro. In: SEMINÁRIO DE GESTÃO DE NEGÓCIOS, 1, 2004, Curitiba Anais... Curitiba-Paraná, 2004.

ROSSETTO, C. R. Adaptação estratégica organizacional: um estudo multi-caso na indústria da construção civil - setor de edificações. 1998. 194 fl. Tese (Doutorado em Engenharia de Produção) - Universidade Federal de Santa Catarina. 1998.

ROSSETTO, C. R.; ROSSETTO, A. M. Teoria institucional e dependência de recursos na adaptação organizacional: uma visão complementar. RAE-Eletrônica, São Paulo, v. 4, n. 1, p. 65-87, jan./jun. 2005.

ROSSETTO, C. R.; CUNHA, C. J. C. A.; ORSSATTO, C. H. Os stakeholders no processo de adaptação estratégica: um estudo longitudinal. Teoria e Evidência Econômica, Passo Fundo, v. 5, n. 9, p. 107-126, maio 1997.

ROSSETTO, P. D. C. R.; LAZZARETTI, K.; VARGAS, S. M. L. Adaptação estratégica em uma instituição de educação profissional. Revista de Administração FACES Journal, Belo Horizonte, v. 11, n. 2, p. 108-129, 2012.

SAUSEN, J. O. Adaptação estratégica organizacional: um estudo histórico - interpretativo. $R e$ vista Desenvolvimento em Questão, Ijuí, v. 1, n. 2, p. 203-230, jul./dez. 2003.

SAUSEN, J. O.; TRETER, J.; WBATUBA, B. B. R. As estratégias de mudança e recuperação de uma importante cooperativa de produção do complexo do agribusiness gaúcho. In: ENCONTRO ANUAL DA ANPAD, 28, 2004, Curitiba. Anais... Curitiba-Paraná: Anpad, 2004.

SCHMIDT, S.; COSTA, P. A.; FREITAS, E. C. Mudanças estratégicas das empresas calçadistas do Vale do Rio dos Sinos. Organizações \& Sociedade, Bahia, v. 18, n. 58, p. 371-388, 2014.

SELZNICK, P. TVA and the grass roots. Berkeley: University of California Press, 1955.

THOMPSON, J. D. Organizations in action. New York: McGraw Hill, 1967.

TRIVIÑOS, A. N. S. Introdução à pesquisa em ciências sociais: a pesquisa qualitativa em educação. São Paulo: Atlas, 1987.

ZUCKER, L. G.. The role of institutionalization in cultural persistence. American Sociological Review, Los Angeles, v. 42, p. 726-743, 1977.

WHITTINGTON, R. Environmental structure and theories of strategic choice. Journal of Management Studies, Oxford, n. 25, v. 6, p. 1-17, 1988.

. O que é estratégia. São Paulo: Pioneira Thomson Learning, 2002. 